\title{
The Usefulness of Postoperative Direct Voice Therapy in Vocal Polyps
}

\author{
Dong Ju Oh, So Yeon Kim, In Hak Choi, Hye Min Han, \\ Hyung Kwon Byeon, Kwang Yoon Jung, and Seung Kuk Baek \\ Department of Otolaryngology-Head and Neck Surgery, Korea University College of Medicine, Seoul, Korea
}

\author{
성대폴립 환자에서 수술 후 음성치료의 유효성 \\ 오동주 · 김소연 · 최인학 · 한혜민 · 변형권 · 정광윤 · 백승국 \\ 고려대학교 의과대학 이비인후과학교실
}

\author{
Received June 7, 2018 \\ Revised July 11, 2018 \\ Accepted July 23, 2018 \\ Address for correspondence \\ Seung Kuk Baek, MD, PhD \\ Department of Otolaryngology- \\ Head and Neck Surgery, \\ Korea University \\ College of Medicine, \\ 145 Anam-ro, Seongbuk-gu, \\ Seoul 02841, Korea \\ Tel $+82-2-920-5345$ \\ Fax $+82-2-925-5233$ \\ E-mail mdskbaek@gmail.com
}

Background and Objectives Previous studies have suggested the usefulness and importance of postoperative voice therapy, for which there are indirect and direct methods. The aim of this study was to evaluate the efficacy of treatment according to different voice therapy methods.

Subjects and Method Patients with vocal polyp were divided into three groups. Group 1 received direct voice therapy after phonomicrosurgery and Group 2 indirect voice therapy after phonomicrosurgery. Group 3 did not receive any voice therapy.

Results Perceptual, acoustic, aerodynamic voice outcome parameters differed significantly between pre and post-operative treatments. In almost all of the voice analysis, Group 1, who underwent direct voice therapy, improved more significantly compared with Group 2 and 3.

Conclusion Postoperative voice therapy following phonomicrosurgery may be an effective adjuvant treatment in patients with vocal polyps. In particular, direct voice therapy can be effective for improving postoperative voice outcome.

Korean J Otorhinolaryngol-Head Neck Surg 2018;61(12):686-91

Key Words Phonomicrosurgery · Vocal polyp · Voice therapy.

\section{서 론}

대부분의 음성 문제는 음성의 오용과 성대의 구조적 변화 로 인한 과기능적인 음성 사용 습관으로 발생하며, 이로 인 해 부적절한 음도와 강도, 애성이 동반된다.1) 과기능적 음성 사용은 성대에 과도한 접촉을 유발하여 고유층의 표층에 병 리적 변화를 일으켜 성대용종을 유발한다. ${ }^{2,3)}$

성대용종의 치료는 후두미세수술로 성대 병변을 제거하는 것이 기본 원칙이다. ${ }^{4.5)}$ 하지만 성대용종 발생의 주된 원인이

This is an Open Access article distributed under the terms of the Creative Commons Attribution Non-Commercial License (https://creativecommons.org/licenses/by-nc/4.0) which permits unrestricted non-commercial use, distribution, and reproduction in any medium, provided the original work is properly cited.
음성남용일 경우 음성치료를 병행하는 것이 좋다고 보고된 바 있다. ${ }^{6}$ 수술적인 치료만 할 경우, 음성을 사용하는 과기능 적인 측면에서 변화가 이루어지지 않아 병변의 재발 가능성 이 높기 때문이다. 따라서 수술 이후 과기능적 음성사용을 예 방하기 위해 수술적 치료와 음성치료를 병행하는 것이 바람 직한 치료로 제시되고 있다. ${ }^{7-9)}$

$\mathrm{Ju}$ 등 $^{10)}$ 은 음성치료를 받은 환자에서 음성장애지수(voice handicap index, VHI)가 음성치료를 받지 않은 환자보다 개선 되었다고 보고하였다. You 등 ${ }^{11}$ 도 후두미세수술 후 음성치료 를 받은 환자에서 VHI, dysphonia severity index가 음성치 료를 받지 않은 환자보다 개선되었다고 보고하였다.

음성치료 방법은 전통적으로 간접치료, 직접치료로 나뉜다. 
간접치료는 음성장애가 과도한 음성 사용, 건강한 음성 산출 방법에 대한 이해 부족, 스트레스 등의 개인적인 요인 때문에 발생한다는 것을 전제로 하여 환자가 음성 산출에 대한 기본 지식을 이해하고 생활방식을 수정해서 건강한 음성 산출을 할 수 있도록 도움을 준다. ${ }^{12-14)}$ 간접치료에는 음성 위생, 음성 휴식, 수분 섭취, 이완기법, 환자 교육 등이 포함된다. 직접치료 는 음성 효율 및 음질을 개선시키는 방법에 초점을 맞춰 나쁜 음성 산출 습관을 수정하고 후두의 병리적 상태를 개선시키 는 데 목적을 둔다. ${ }^{12,13)}$ 성대 과기능의 경우 성대에 힘을 덜 줄 수 있도록 고안된 방법을 통해 음성 산출을 개선시킨다. 직 접치료기법은 호흡, 발성, 공명 등 음성 산출 요소간에 적절 한 균형을 이루게 하며 후두근육의 균형, 근력, 긴장도를 개선 시키고 성대 점막표면이 건강하게 기능할 수 있도록 돕는다. ${ }^{14)}$ 앞선 연구에서 보듯이 후두미세수술 후 음성치료를 하는 것이 음성개선에 도움이 되는 것을 알 수 있다. 대부분의 음성 치료는 간접치료와 직접치료를 병행했을 때 치료 효과가 크 다고 알려져 있는데 성대용종 환자에서 후두미세수술 후 음 성치료를 간접, 직접치료로 나눠 치료 효과를 비교한 바는 없었다. 따라서 본 연구는 후두미세수술 후 음성치료 방법에 따른 청지각적, 음향학적, 음역대검사(voice range profile, $\mathrm{VRP})$, 공기역학적, 음성장애지수(VHI) 수치의 변화를 살펴 보고자 한다.

\section{대상 및 방법}

\section{대 상}

2013년 9월부터 2015년 6월까지 쉰 목소리를 주소로 본원 이비인후과를 방문하여 성대용종으로 진단받고 후두미세수 술을 받은 354 명의 환자들을 대상으로 후향적 분석을 수행 하였다. 성대용종 치료는 과거에 후두미세수술만 시행하였는 데 이후 간접치료를 추가하였고 나중에 직접치료를 같이 병 행하는 치료 방법으로 바뀌었다. 후두미세수술 후 환자의 음 성치료 거부 등에 의해서도 치료방법이 결정되었다. 후두미세 수술 후 간접치료와 직접치료를 받은 환자(G1)는 108명, 후 두미세수술 후 간접치료를 받은 환자는(G2) 95명, 후두미세 수술만 받은 경우(G3) 151명이었다. 이 중에 양측성 성대용종 이나 반대측에 성대결절이 동반되었을 경우, 라인케씨 부종 이 있는 경우를 제외하였고 음성요구가 필요한 직업을 가진 20세 이상의 편측 성대용종 환자 중 수술 전, 수술 8주 후 음 성검사를 시행한 환자만을 대상으로 하였다. 최종적으로 후 두미세수술 후 간접치료와 직접치료를 받은 환자(G1) 44명, 후두미세수술 후 간접치료를 받은 환자(G2) 42명, 후두미세 수술만 받은 환자(G3) 44명이 연구에 포함되었다. 본 연구는
고려대학교 안암병원 임상시험심사위원회의 검토와 승인을 받았다(승인번호: 2018AN0229).

\section{수술 및 음성재활}

모든 환자에서 후두미세수술은 동일한 수술자에 의해 전 신마취하에 이루어졌으며 성대의 정상적인 점막 구조물을 최대한 보존하면서 성대용종이 제거되었다.

모든 환자는 술 후 1 주간 절대 음성안정을 취했으며 술 후 2 3주간 점차적으로 발성하도록 교육받았다. 음성치료 방법 에 따라 환자를 세 집단으로 나누었다. 첫 번째 집단(G1)은 후두미세수술 1주 후부터 4주 동안 직접치료를 1 2회 실시 하였고 치료는 한 회당 40 분 동안 진행되었다. 두 번째 집단 (G2)은 후두미세수술 후 1 2회 간접치료(음성위생교육)만 실시하였다. 세 번째 집단(G3)은 후두미세수술 후 음성치료 를 받지 않았다.

\section{음성치료}

G1은 후두미세수술 후 간접치료와 직접치료를 받은 집단 으로 음성위생교육을 포함하여 복식호흡훈련, 이완훈련, 후 두마사지, 공명발성훈련을 시행하였다. 부드러운 이완 발성을 위해 음성의 강도를 60 65 dB로 하였으며 문장 및 대화수준 에서 훈련을 하여 일반화를 할 수 있도록 유도하였다. 또한 성 대근 강화와 탄력성 증진을 위하여 성대기능훈련(vocal function exercise)을 함께 병행하였다.

$\mathrm{G} 2$ 는 수술 후 간접치료만 받은 군으로 목에 이물감이 있 을 경우, 환자에게 헛기침하는 대신에 침을 삼키거나 물을 마 시도록 교육하였다. 발성 습관과 관련된 측면에서는 목에 힘 을 주어 큰 소리로 노래하거나 말하는 것을 삼가고 속삭이듯 발성하지 않도록 하였다. 신체적인 측면에서는 성대가 건조하 지 않기 위해 하루 8 10잔 이상의 물을 자주 마시도록 하였 다. 또한, 수술 후 음성 사용을 점진적으로 늘려갈 수 있도록 안내해주었다.

\section{평가 방법}

모든 대상자들은 수술 전과 수술 8주 후 음성검사를 시행 하였다. 청지각적 평가는 GRBAS scale(Grade, Roughness, Breathiness, Asthenia, Strain) 중에 Grade, Roughness, Breathiness를 이용하였고 음향학적 평가를 위해 Computerized Speech Lab, Model 4500, KayPENTAS elementrics (KayPENTAX Corp., Lincoln Park, NJ, USA)의 MultiDimensional Voice Program을 이용하여 주파수변동률(jitter), 진폭변동률(shimmer), 잡음 조화비(noise to harmonic ratio, NHR)를 분석하였다. 음역대검사(voice range profile) 
측정을 위해서 환자의 입과 마이크의 거리를 $15 \mathrm{~cm}$ 로 유지 한 후 최저음도에서 최고음도까지 모음 /a/를 통해 낮은음에 서 높은음, 높은음에서 낮은음으로 각각 음의 영역(range)을 측정하였다. 이후 각각의 음도(pitch)를 검사 기계를 통해 환 자에게 들려주면서 음계에 맞게 발성하도록 하며 각 음도의 강도를 측정하였다. 측정치의 대표 변수인 maximum pitch, minimum pitch, maximum loudness, minimum loudness 를 통해 분석하였고 공기역학적 평가는 Phonatory Aerodynamic System Model 6600, Kay PENTAS Elemetrics를 이용하여 최장발성시간(maximum phonation time, MPT), 최 대호기율(maximum airflow rate, MFR), 성문하압(subglottal pressure, Psub)을 분석하였다. 환자의 주관적인 음성장애 평 가를 위해 음성장애지수(VHI)를 이용하였다. VHI는 신체적 (physical) 영역, 기능적(functional)영역, 감정적(emotional)영 역으로 나뉘어져 있고 장애의 정도에 따라 각각 0 4점으로 체크하도록 하였다.

\section{통계 분석}

통계 분석은 SPSS 18.0(SPSS Inc., Chicago, IL, USA)을 사용하였다. 집단 간 환자의 연령, 성별 및 수술 전 음성 분석 에는 one way analysis of variance(ANOVA)를 사용하였 다. Paired t-test를 통해 후두미세수술 전후 유의한 차이가 있
는지 살펴보았고 repeated measure ANOVA를 통해 후두미 세수술 후 집단 간에 유의한 차이가 있는지 살펴보았다.

\section{결 과}

\section{연령, 성별분포 및 후두미세수술 전 음성 분석}

대상 환자의 평균 연령은 42.9세였고 여성 63명, 남성 67명 이었다. 집단 간의 성별 및 나이에는 유의한 차이를 보이지 않 았고 후두미세수술 전 음성검사에서도 집단 간에 유의한 차 이를 보이지 않았다(Table 1).

\section{후두미세수술 전후 음성 분석}

후두미세수술 전후 청지각적, 음향학적, 음역대검사, 공기 역학적, 음성장애지수 값을 비교한 결과 청지각적 분석은 세 집단 모두 Grade, Rough, Breathy에서 후두미세수술 후 유 의한 감소를 보였다(Table 2). 음향학적 검사결과, G1는 jitter, shimmer, NHR에서 수술 후 유의한 감소를 보였으나 G2는 jitter, NHR에서 유의한 차이를 보였으며 G3는 jitter에서만 유 의한 차이를 보였다(Table 3). VRP 검사결과, G1은 maximum pitch, minimum pitch에서 수술 전후로 유의한 변화를 보였 지만 G2는 유의한 차이를 보이지 않았고 G3는 minimum pitch에서만 유의한 차이를 보였다. maximum loudness와

Table 1. Demographics of the patients and comparison of preoperative parameters between three groups

\begin{tabular}{|c|c|c|c|c|}
\hline & G1 $(n=44)$ & $\mathrm{G} 2(\mathrm{n}=42)$ & G3 $(n=44)$ & $p$ value \\
\hline Gender & & & & 0.970 \\
\hline Male & 23 & 22 & 22 & \\
\hline Female & 21 & 20 & 22 & \\
\hline Mean age & $41.73 \pm 10.42$ & $44.05 \pm 8.78$ & $43.00 \pm 9.25$ & 0.528 \\
\hline Grade & $2.71 \pm 0.55$ & $2.67 \pm 0.48$ & $2.61 \pm 0.49$ & 0.703 \\
\hline Roughness & $2.05 \pm 0.89$ & $2.19 \pm 0.74$ & $2.25 \pm 0.65$ & 0.440 \\
\hline Breathiness & $2.14 \pm 0.80$ & $2.19 \pm 0.77$ & $2.18 \pm 0.76$ & 0.941 \\
\hline Jitter & $2.94 \pm 1.73$ & $3.18 \pm 1.77$ & $3.27 \pm 1.66$ & 0.637 \\
\hline Shimmer & $7.36 \pm 4.04$ & $7.32 \pm 4.38$ & $7.28 \pm 2.37$ & 0.994 \\
\hline NHR & $0.21 \pm 0.09$ & $0.22 \pm 0.22$ & $0.21 \pm 0.26$ & 0.965 \\
\hline Maximum pitch & $295.77 \pm 71.96$ & $305.87 \pm 99.90$ & $299.58 \pm 86.25$ & 0.862 \\
\hline Minimum pitch & $139.50 \pm 31.03$ & $134.49 \pm 37.66$ & $141.37 \pm 37.66$ & 0.625 \\
\hline Maximum loudness & $95.41 \pm 7.60$ & $97.79 \pm 9.51$ & $95.75 \pm 5.59$ & 0.308 \\
\hline Minimum loudness & $74.57 \pm 9.83$ & $77.23 \pm 9.25$ & $73.80 \pm 11.36$ & 0.266 \\
\hline MFR & $233.73 \pm 63.68$ & $235.00 \pm 54.29$ & $235.00 \pm 75.00$ & 0.975 \\
\hline MPT & $10.57 \pm 4.33$ & $10.68 \pm 3.78$ & $10.66 \pm 4.04$ & 0.991 \\
\hline Psub & $16.98 \pm 6.78$ & $15.72 \pm 4.26$ & $15.94 \pm 4.87$ & 0.516 \\
\hline VHI-functional & $11.43 \pm 4.29$ & $11.38 \pm 5.20$ & $12.09 \pm 5.05$ & 0.749 \\
\hline VHI-physical & $21.09 \pm 6.48$ & $22.38 \pm 7.06$ & $22.32 \pm 7.32$ & 0.622 \\
\hline VHI-emotional & $8.46 \pm 5.25$ & $10.29 \pm 5.98$ & $11.07 \pm 7.97$ & 0.159 \\
\hline
\end{tabular}

G1: group who was treated with direct voice therapy, G2: group with indirect voice therapy, G3: group without any postoperative voice therapy, NHR: noise to harmonic ratio, MFR: maximum airflow rate, MPT: maximum phonation time, Psub: subglottal pressure, VHI: voice handicap index 
minimum loudness는 세 집단 모두에서 유의한 차이를 보이 지 않았다(Table 4). 공기역학적 검사결과, 모든 집단에서 MPT, Psub이 수술 후 유의한 차이를 보였으나 MFR은 G1 에서만 유의한 차이를 보였다(Table 5). 음성장애지수 설문지

Table 2. Perceptual analysis before and after surgery

\begin{tabular}{lcccc}
\hline Parameter & Groups & Preoperative & Postoperative & p value \\
\hline Grade & G1 & $2.71 \pm 0.55$ & $0.64 \pm 0.72$ & $<0.001^{*}$ \\
& G2 & $2.67 \pm 0.48$ & $0.88 \pm 0.83$ & $<0.001^{*}$ \\
Roughness & G3 & $2.61 \pm 0.49$ & $0.91 \pm 0.64$ & $<0.001^{*}$ \\
& G1 & $2.05 \pm 0.89$ & $0.32 \pm 0.52$ & $<0.001^{*}$ \\
& G2 & $2.19 \pm 0.74$ & $0.62 \pm 0.83$ & $<0.001^{*}$ \\
Breathiness & G3 & $2.25 \pm 0.65$ & $0.52 \pm 0.59$ & $<0.001^{*}$ \\
& G1 & $2.14 \pm 0.80$ & $0.55 \pm 0.73$ & $<0.001^{*}$ \\
& G2 & $2.19 \pm 0.77$ & $0.64 \pm 0.76$ & $<0.001^{*}$ \\
& G3 & $2.18 \pm 0.76$ & $0.80 \pm 0.70$ & $<0.001^{*}$ \\
\hline
\end{tabular}

$* p<0.001$. G1: group with was treated with direct voice therapy, G2: group with indirect voice therapy, G3: group without any postoperative voice therapy

Table 3. Acoustic analysis before and after surgery

\begin{tabular}{lcccc}
\hline Parameter & Groups & Preoperative & Postoperative & p value \\
\hline Jitter & G1 & $2.94 \pm 1.73$ & $1.60 \pm 3.18$ & $0.035^{*}$ \\
& G2 & $3.18 \pm 1.77$ & $1.35 \pm 1.93$ & $<0.001^{\dagger}$ \\
Shimmer & G3 & $3.27 \pm 1.66$ & $1.33 \pm 0.20$ & $<0.001^{\dagger}$ \\
& G1 & $7.36 \pm 4.04$ & $2.92 \pm 1.44$ & $<0.001^{\dagger}$ \\
& G2 & $7.32 \pm 4.38$ & $5.79 \pm 2.22$ & 0.053 \\
NHR & G3 & $7.28 \pm 2.37$ & $7.00 \pm 2.44$ & 0.408 \\
& G1 & $0.21 \pm 0.09$ & $0.14 \pm 0.09$ & $0.001^{*}$ \\
& G2 & $0.22 \pm 0.22$ & $0.13 \pm 0.09$ & $0.025^{*}$ \\
& G3 & $0.21 \pm 0.26$ & $0.15 \pm 0.05$ & 0.178 \\
\hline
\end{tabular}

$* p<0.05,+p<0.001 . G 1$ : group who was treated with direct voice therapy, G2: group with indirect voice therapy, G3: group without any postoperative voice therapy, NHR: noise to harmonic ratio

Table 4. Voice range profile analysis before and after surgery

\begin{tabular}{ccccc}
\hline Parameter & Groups & Preoperative & Postoperative & p value \\
\hline $\begin{array}{c}\text { Maximum } \\
\text { pitch }\end{array}$ & G1 & $295.77 \pm 71.96$ & $474.19 \pm 101.16$ & $<0.001^{\dagger}$ \\
& G2 & $305.87 \pm 99.90$ & $324.54 \pm 80.74$ & 0.096 \\
Minimum & G3 & $299.58 \pm 86.25$ & $308.23 \pm 71.98$ & 0.289 \\
pitch & G2 & $139.50 \pm 31.03$ & $120.92 \pm 28.35$ & $<0.001^{\dagger}$ \\
& G3 & $141.37 \pm 37.66$ & $133.33 \pm 34.92$ & $0.042^{*}$ \\
Maximum & G1 & $95.41 \pm 7.60$ & $95.21 \pm 3.31$ & 0.847 \\
loudness & G2 & $97.79 \pm 9.51$ & $97.00 \pm 7.89$ & 0.558 \\
& G3 & $95.75 \pm 5.59$ & $95.00 \pm 4.10$ & 0.404 \\
Minimum & G1 & $74.57 \pm 9.83$ & $72.71 \pm 6.90$ & 0.176 \\
loudness & G2 & $77.23 \pm 9.25$ & $75.02 \pm 8.41$ & 0.118 \\
& G3 & $73.80 \pm 11.36$ & $71.23 \pm 3.88$ & 0.107 \\
\hline
\end{tabular}

$* p<0.05,+p<0.001 . G 1$ : group who was treated with direct voice therapy, G2: group with indirect voice therapy, G3: group without any postoperative voice therapy
에서는 세 집단 모두 functional, emotion 영역에서 수술 전 후 유의한 차이를 보였으나 physical 영역은 G1과 G2에서만 유의한 차이를 보였다(Table 6).

\section{후두미세수술 후 음성 치료 방법에 따른 집단 간 비교}

음성치료 방법에 따른 집단 간 차이를 분석한 결과 진폭변 동률(G1 vs. G2 vs. G3: $2.91 \pm 1.44$ vs. $5.79 \pm 2.22$ vs. $7.00 \pm$ 2.44), maximum pitch(G1 vs. G2 vs. G3: $474.19 \pm 101.16$ vs. $324.54 \pm 80.74$ vs. $308.23 \pm 71.98$ ), 최대호기율(G1 vs. G2 vs. G3: $168.41 \pm 71.17$ vs. $218.33 \pm 88.01$ vs. $220.68 \pm 77.35)$, 최대 발성시간(G1 vs. G2 vs. G3: $19.67 \pm 19.33$ vs. $13.23 \pm 3.41$ vs. $15.53 \pm 5.22$ ), 음성장애지수의 신체적 영역(G1 vs. G2 vs. G3: $4.98 \pm 7.54$ vs. $11.33 \pm 10.98$ vs. $20.80 \pm 6.89)$ 에서 유의한 차이 를 보였다(Table 7).

\section{고 찰}

본 연구에서는 성대용종 환자를 대상으로 후두미세수술

Table 5. Aerodynamic analysis before and after surgery

\begin{tabular}{ccccc}
\hline Parameter & Groups & Preoperative & Postoperative & p value \\
\hline MFR & G1 & $233.73 \pm 63.68$ & $168.41 \pm 71.17$ & $<0.001^{\dagger}$ \\
& G2 & $235.00 \pm 54.29$ & $218.33 \pm 88.01$ & 0.254 \\
MPT & G3 & $235.00 \pm 75.00$ & $220.68 \pm 77.35$ & 0.338 \\
& G1 & $10.57 \pm 4.33$ & $19.67 \pm 19.33$ & $0.002^{*}$ \\
& G2 & $10.68 \pm 3.78$ & $13.23 \pm 3.41$ & $0.002^{*}$ \\
Psub & G3 & $10.66 \pm 4.04$ & $15.53 \pm 5.22$ & $<0.001^{\dagger}$ \\
& G1 & $16.98 \pm 6.78$ & $10.52 \pm 3.85$ & $<0.001^{\dagger}$ \\
& G2 & $15.72 \pm 4.26$ & $11.20 \pm 4.04$ & $<0.001^{\dagger}$ \\
& G3 & $15.94 \pm 4.87$ & $11.35 \pm 5.32$ & $<0.001^{\dagger}$
\end{tabular}

$* p<0.05, t p<0.001$. G1: group who was treated with direct voice therapy, G2: group with indirect voice therapy, G3: group without any postoperative voice therapy, MFR: maximum airflow rate, MPT: maximum phonation time, Psub: subglottal pressure

Table 6. Voice handicap index analysis before and after surgery

\begin{tabular}{ccccc}
\hline Parameter & Groups & Preoperative & Postoperative & p value \\
\hline Functional & G1 & $11.43 \pm 4.29$ & $2.91 \pm 7.44$ & $<0.001^{*}$ \\
& G2 & $11.38 \pm 5.20$ & $5.26 \pm 8.28$ & $<0.001^{*}$ \\
& G3 & $12.09 \pm 5.05$ & $3.86 \pm 7.24$ & $<0.001^{*}$ \\
Physical & G1 & $21.09 \pm 6.48$ & $4.98 \pm 7.54$ & $<0.001^{*}$ \\
& G2 & $22.38 \pm 7.06$ & $11.33 \pm 10.98$ & $<0.001^{*}$ \\
& G3 & $22.32 \pm 7.32$ & $20.80 \pm 6.89$ & 0.152 \\
Emotional & G1 & $8.46 \pm 5.25$ & $2.61 \pm 6.62$ & $<0.001^{*}$ \\
& $G 2$ & $10.29 \pm 5.98$ & $3.19 \pm 9.37$ & $<0.001^{*}$ \\
& G3 & $11.07 \pm 7.97$ & $3.52 \pm 7.18$ & $<0.001^{*}$
\end{tabular}

$* p<0.001$. G1: group who was treated with direct voice therapy, G2: group with indirect voice therapy, G3: group without any postoperative voice therapy 
Table 7. Comparison of postoperative parameters between three groups

\begin{tabular}{|c|c|c|c|c|}
\hline & G1 $(n=44)$ & $\mathrm{G} 2(\mathrm{n}=42)$ & G3 $(n=44)$ & $p$ value \\
\hline Grade & $0.64 \pm 0.72$ & $0.88 \pm 0.83$ & $0.91 \pm 0.64$ & 0.164 \\
\hline Roughness & $0.32 \pm 0.52$ & $0.62 \pm 0.83$ & $0.52 \pm 0.59$ & 0.096 \\
\hline Breathiness & $0.55 \pm 0.73$ & $0.64 \pm 0.76$ & $0.80 \pm 0.70$ & 0.273 \\
\hline Jitter & $1.60 \pm 3.18$ & $1.35 \pm 1.93$ & $1.33 \pm 0.20$ & 0.624 \\
\hline Shimmer & $2.91 \pm 1.44$ & $5.79 \pm 2.22$ & $7.00 \pm 2.44$ & $<0.001^{\dagger}$ \\
\hline NHR & $0.14 \pm 0.09$ & $0.13 \pm 0.09$ & $0.15 \pm 0.05$ & 0.485 \\
\hline Maximum pitch & $474.19 \pm 101.16$ & $324.54 \pm 80.74$ & $308.23 \pm 71.98$ & $<0.001^{\dagger}$ \\
\hline Minimum pitch & $120.92 \pm 28.35$ & $125.80 \pm 34.69$ & $133.33 \pm 34.92$ & 0.206 \\
\hline Maximum loudness & $95.21 \pm 6.61$ & $97.00 \pm 7.89$ & $95.00 \pm 4.10$ & 0.284 \\
\hline Minimum loudness & $72.71 \pm 6.90$ & $75.02 \pm 8.41$ & $71.23 \pm 3.88$ & $0.031^{*}$ \\
\hline MFR & $168.41 \pm 71.17$ & $218.33 \pm 88.01$ & $220.68 \pm 77.35$ & $0.003^{*}$ \\
\hline MPT & $19.67 \pm 19.33$ & $13.23 \pm 3.41$ & $15.53 \pm 5.22$ & $0.040 *$ \\
\hline Psub & $10.52 \pm 3.85$ & $11.20 \pm 4.04$ & $11.35 \pm 5.32$ & 0.652 \\
\hline VHI-functional & $2.91 \pm 7.44$ & $5.26 \pm 8.28$ & $3.86 \pm 7.24$ & 0.362 \\
\hline VHI-physical & $4.98 \pm 7.54$ & $11.33 \pm 10.98$ & $20.80 \pm 6.89$ & $<0.001^{\dagger}$ \\
\hline VHI-emotional & $2.61 \pm 6.62$ & $3.19 \pm 7.37$ & $3.52 \pm 7.18$ & 0.837 \\
\hline
\end{tabular}

$* p<0.05,{ }^{\dagger} p<0.001$. NHR: noise to harmonic ratio, MFR: maximum airflow rate, MPT: maximum phonation time, Psub: subglottal pressure, $\mathrm{VHI}$ : voice handicap index

후 음성치료 방법에 따라 음성회복에 차이가 있는지 살펴보았 다. 후두미세수술 전후 집단별 음성 분석에 대한 결과를 살 펴보았을 때, 직접치료를 실시한 G1에서는 음향학적, 청지각 적, 공기역학적, 음성장애지수에서 모두 유의한 차이를 보였 다. 하지만 간접치료를 실시한 $\mathrm{G} 2$ 에서는 진폭변동률, maximum pitch, minimum pitch, 최대호기율에서 유의한 차이 를 보이지 않았다. 음성치료를 받지 않은 G3는 진폭변동률, 잡음조화비, maximum pitch, 최대호기율, 음성장애지수 신 체적 영역에서 유의한 차이를 보이지 않았다.

이는 성대용종 환자들을 대상으로 후두미세수술을 시행 하였을 때 최장발성시간, 주파수변동률, 진폭변동률, 잡음조 화비 값에서 유의한 호전을 보임으로써 성대용종 환자들은 대부분 수술적인 치료로서 정상범위의 음질을 찾을 수 있다 고 보고한 연구결과와 비슷하다. ${ }^{15,16)}$ 음성장애의 심각성과 성 대용종의 치료 판정에 도움을 주는 변수인 주파수변동률과 진폭변동률은 성대의 비대칭성, 공기흐름의 장애 등과 같은 성대의 안정과 관련되어 있으므로 매우 중요한 변수 중 하나 이다. ${ }^{17,18)}$ 특히, 진폭변동률은 청지각적으로 쉰소리(breathy) 와 최대호기율은 발성 시 산출되는 기류량과 밀접한 관련되 어 있으므로 성대 접촉이 일관적이지 않을 경우 이들 값이 증가한다. ${ }^{15)}$ 본 연구에서 직접치료를 시행한 $\mathrm{G} 1$ 에서는 진폭 변동률과 최대호기율에서 모두 유의한 차이를 보였지만 간 접치료를 실시한 $\mathrm{G} 2$ 에서는 수술 전후 차이를 보이지 않았다. 즉, 직접치료를 실시한 집단에서는 복식호흡 및 부드러운 성 대 접촉을 유도하는 연습을 하였기 때문에 수술 후 비일관적
인 성대접촉을 줄이면서 음질적인 측면에서 개선을 보인 것 으로 해석할 수 있다.

후두미세수술 전후 음성치료 방법에 따른 비교에서 음역 대검사를 살펴보았을 때, G1에서만 수술 전후 maximum pitch 값의 유의미한 증가와 minimal pitch 값의 유의미한 감소를 보여 전체적인 음역대의 유의미한 증가를 관찰할 수 있었다. 이는 직접치료를 받음으로써 진폭변동률과 최대호기 율이 개선된 것과 마찬가지로 직접치료가 maximum pitch, minimal pitch를 개선시키는데 영향을 주는 것으로 생각할 수 있겠다.

본 연구에서는 음성치료를 받은 $\mathrm{Gl}, \mathrm{G} 2$ 에서 치료 전에 비 해 치료 후 음성장애지수(VHI)의 모든 영역에서 의미 있는 호전을 보였다. 이는 수술 후 음성치료를 받은 집단과 받지 않은 집단에서 음성장애지수 모든 값에서 개선을 보인 이전 연구와 같은 결과를 보였다. ${ }^{10,11)}$ 이 중에 신체적 영역은 신체 적 통증과 후두 부위의 불편감 음성 특성에 대한 인식도와 관련이 있는 값으로, 직접치료, 간접치료 집단간에도 유의한 차이를 보여 직접치료가 환자의 신체적 불편감을 줄이는데 간접치료보다 더 효과적임을 확인할 수 있었다.

치료 8 주 후 음성치료 방법에 따른 집단 간 음성분석을 살 펴보면 진폭변동률, maximum pitch, 최대호기율, 최대발성 시간, 음성장애지수의 신체적 영역에서 직접치료와 간접치료 를 병행한 G1에서 가장 개선된 수치를 보였고 G2가 G3보다 더 좋은 결과를 보임을 알 수 있었다(Table 7).

본 연구에서 성대용종 환자에서 수술만으로도 음성 개선 
에 효과가 있지만 간접치료, 직접치료를 병행했을 때 음성개 선의 효과가 더 있음을 알 수 있었다. 또한 수술 후 음성위생 교육만 시행하는 것보다 적극적인 음성치료를 시행했을 때 더 효과적임을 알 수 있었다.

\section{REFERENCES}

1) Ramig LO, Verdolini K. Treatment efficacy: voice disorders. J Speech Lang Hear Res 1998;41(1):S101-16.

2) Kim ST, Jeong GE, Kim SY, Choi SH, Lim GC, Han JH, et al. The effect of voice therapy in vocal polyp patients. Phonetics and Speech Sciences 2009;1(2):43-9.

3) Johns MM. Update on the etiology, diagnosis, and treatment of vocal fold nodules, polyps, and cysts. Curr Opin Otolaryngol Head Neck Surg 2003;11(6):456-61.

4) Jensen JB, Rasmussen N. Phonosurgery of vocal fold polyps, cysts and nodules is beneficial. Dan Med J 2013;60(2):A4577.

5) Uloza V, Saferis V, Uloziene I. Perceptual and acoustic assessment of voice pathology and the efficacy of endolaryngeal phonomicrosurgery. J Voice 2005;19(1):138-45.

6) Kim ST, Jeong OR, Ahn CM. The effects of SKMVTT ${ }^{\circledR}$ on voice improvement in vocal polyp patients. Speech Sciences 2008;15(2): 157-68.

7) Yun YS, Kim MB, Son YI. The effect of vocal hygiene education for patients with vocal polyp. Otolaryngol Head Neck Surg 2007; 137(4):569-75.

8) Kim HG, Chung PS, Oh YH, Kim YH. A study of voice improvement according to the onset time of voice therapy after laryngomicrosurgery.
J Korean Soc Laryngol Phoniatr Logop 2001;12(1):22-7.

9) Sulica L, Behrman A. Management of benign vocal fold lesions: a survey of current opinion and practice. Ann Otol Rhinol Laryngol 2003;112(10):827-33.

10) Ju YH, Jung KY, Kwon SY, Woo JS, Cho JG, Park MW, et al. Effect of voice therapy after phonomicrosurgery for vocal polyps: a prospective, historically controlled, clinical study. J Laryngol Otol 2013;127(11): 1134-8.

11) You H, Zhuge P, Wang H, Zhang Y, Du H. Clinical observation of the effect of voice training on patients with vocal cord polyps after phonomicrosurgery. Biomed Res 2017;28(9):3874-9.

12) Carding PN, Horsley IA, Docherty GJ. The effectiveness of voice therapy for patients with non-organic dysphonia. Clin Otolaryngol Allied Sci 1998;23(4):310-8.

13) Rattenbury HJ, Carding PN, Finn P. Evaluating the effectiveness and efficiency of voice therapy using transnasal flexible laryngoscopy: a randomized controlled trial. J Voice 2004;18(4):522-33.

14) Thomas LB, Stemple JC. Voice therapy: does science support the art? Communicative Disorders Review 2007;1(1):51-79.

15) Hong JC, Lee KD, Kim WS, Jang AL, Kim KA, Kwon SB. Voice analysis of vocal polyp and vocal nodule before and after microlaryngeal surgery. J Korean Soc Laryngol Phoniatr Logop 2009;20(1):42-6.

16) Courey MS, Garrett CG, Ossoff RH. Medial microflap for excision of benign vocal fold lesions. Laryngoscope 1997;107(3):340-4.

17) Petrovic-Lazic M, Jovanovic N, Kulic M, Babac S, Jurisic V. Acoustic and perceptual characteristics of the voice in patients with vocal polyps after surgery and voice therapy. J Voice 2015;29(2):241-6

18) Wolfe V, Fitch J, Cornell R. Acoustic prediction of severity in commonly occurring voice problems. J Speech Hear Res 1995;38(2):273-9. 